\title{
Practices in delivery and birth care from mothers' perspective
}

\author{
Práticas na atenção ao parto e nascimento sob a perspectiva das puérperas
}

Débora Apolinário ${ }^{1}$, Marcelexandra Rabelo ${ }^{1}$, Lillian Daisy Gonçalves Wolff ${ }^{1}$, Silvana Regina Rossi Kissula Souza ${ }^{1}$, Giseli Campos Gaioski Leal ${ }^{1}$

Objective: to highlight the practices of delivery and birth care in a maternity ward from mothers' perspective. Methods: descriptive cross-sectional study carried out in a maternity hospital of usual risk, with 100 regular postpartum mothers. It was used a semi-structured questionnaire as recommended by the World Health Organization. Results: among the practices that should be encouraged from birth care, stands out: women's privacy; participation of the companion of their choice; the use of non-pharmacological methods for pain relief. Among the practices that should be eliminated: the transfer to the delivery room at the second stage and the lithotomy position. Conclusion: women are still passive in the birth process despite attempts to change the model of care during labor and birth.

Descriptors: Humanizing Delivery; Nursing; Women's Health.

Objetivo: evidenciar as práticas na atenção ao parto e nascimento em uma maternidade na perspectiva das puérperas. Métodos: pesquisa descritiva transversal realizada em uma maternidade de risco habitual, com 100 puérperas pós-parto normal. Utilizou-se questionário semiestruturado conforme recomendações da Organização Mundial da Saúde. Resultados: dentre as práticas que devem ser estimuladas da assistência ao parto destaca-se: privacidade da mulher; participação do acompanhante de sua escolha; utilização de métodos não farmacológicos de alívio da dor. Entre as práticas que devem ser eliminadas: a transferência para a sala de parto no período expulsivo e a posição de litotomia. Conclusão: as mulheres ainda permanecem passivas no processo de parto, apesar das tentativas em mudar o modelo de atenção ao parto e nascimento.

Descritores: Parto Humanizado; Enfermagem; Saúde da Mulher.

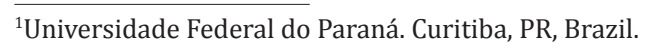




\section{Introduction}

Childbirth is a natural event that does not require control, but care, as highlighted by the guidelines of the World Health Organization. Scientific and technological advances adopted by hospitals aim to prevent morbidity and mortality in childbirth care, but what is still evident are the complications caused exactly by advances and the abusive use of techniques and procedures, generalizing women's bodies, their natural rhythm and preventing women from exercising their key role ${ }^{(1)}$.

In Brazil, with the evolution of public policies for women's health, comprehensive care stands out, and the rescue of birth physiology and humanized care too ${ }^{(2)}$. In 1984, the Ministry of Health launched the Comprehensive Care Program for Women's Health [Programa de Assistência Integral à Saude da Mulher], focused on care actions in the various stages of life ${ }^{(3)}$.

In the 1990s, the Comprehensive Care Program for Women's Health was influenced by propositions of the National Health System, making it a national policy for women's comprehensive care, with care actions that guarantee women's human rights and that could reduce morbidity and mortality due to preventable and avoidable causes ${ }^{(3)}$.

In 2000 the Program for Humanization of Prenatal Care and Birth was launched, a specific program to take care of pregnant women, newborns and mothers, in order to reduce perinatal morbidity and mortality; ensure access, quality and coverage of prenatal care, delivery and postpartum period; expand the service network to risk prenatal care; with emphasis on safe motherhood, work training and humanization of care $^{(2)}$.

Given the evolution of public policies, the Ministry of Health established in 2011 the Stork Network as a strategy to improve obstetric care. This proposal aims to implement a care network to ensure women the right to reproductive planning and humanized attention during pregnancy, childbirth, postpartum period; and to children, the right to a safe birth, growth and healthy development ${ }^{(4)}$.

The Stork Network advocates the humanized care, based on scientific evidence and use of the best practices during delivery and birth. As recommended by the World Health Organization in 1996, by means of a practical guide, categorized as: a) practices that are useful and that should be clearly stimulated; b) clearly harmful or ineffective practices that should be eliminated; c) Practices without sufficient evidence to support a clear recommendation and that should be used carefully until further research clarifying the matter; d) Practices often used improperly ${ }^{(5)}$.

In this perspective, the recommended practices aimed at quality of care, reduction of unnecessary interventions, reduction of maternal and neonatal morbidity and mortality rates in the country. It is noteworthy that these recommendations, when practiced, enable the rescue of women's empowerment, enabling their participation in the decisions about the position during labor and delivery and the presence of their companion during hospitalization ${ }^{(2)}$.

The Stork Network proposes changes in the obstetric care model and it works as a parameter to assess care delivery in institutions. So this study is a means of contributing to the improvement of care given to women by health teams within the obstetrics sphere, observing the practices of care during labor and birth recommended by the World Health Organization aiming at the full humanization of the assistance model. This research may also indicate the practices that should be improved and those that still need to be eliminated from the attention to labor and birth.

Given the above considerations, the aim of this study was to demonstrate the practices in the care to delivery and birth from the perspective of mothers in a public maternity hospital, based on current policies. 


\section{Methods}

This is a descriptive, cross-sectional study, carried out from October 2012 to July 2013, with women interned in a public maternity hospital which is reference to common risk in Curitiba-PR, Brazil.

The sample consisted of 100 participants who met the inclusion criteria: women aged over 18 years old in the immediate postpartum period after the vaginal delivery, admitted to the rooming-in between April and May 2013. And as the exclusion criteria: mothers who had stillbirth or early neonatal mortality.

Data collection was carried out in the rooming-in of the maternity hospital mentioned through a semi-structured questionnaire that was answered individually by the participants and filled in by the researcher. The questionnaire consisted of descriptive variables of the participants (age) and obstetric history (number of pregnancies, number of births); data about the last delivery (gestational age, professional category/qualification of the person who attended her birth in the maternity hospital).

In addition, the questionnaire contained 25 questions regarding the care received in the last delivery, based on the recommendations of the World Health Organization for compliance with labor and delivery ${ }^{(5)}$, highlighting the practices that are clearly useful and should be encouraged and practices that should be eliminated or performed with restraint. In this perspective, the issues addressed about: fasting, use of non-pharmacological methods for pain relief, presence of a partner, place and birth position, skinto-skin contact, breastfeeding within the $1^{\text {st }}$ hour, welcoming and guidelines, as well as those related to procedures or interventions such as shaving, enema, use of oxytocin, amniotomy, episiotomy, analgesia, peripheral venous access.

The data were organized in spreadsheets from the Microsoft ${ }^{\circledR}$ Excel 2007. The descriptive statistical analysis was used, including the absolute frequency and relative frequencies for categorical variables. The results were presented in the form of tables and discussed in the descriptive language.

The study respected the formal requirements contained in the national and international regulatory standards of research involving human subjects.

\section{Results}

The interval of age variable of the 100 participants was from 18 to 37 years old and the gestational age was from 36 to 41 weeks at the moment of delivery. Regarding the number of pregnancies, $39.0 \%$ were primiparous, $39.0 \%$ secondiparous and $22.0 \%$ multiparous.

In the period surveyed there was a nurse and two obstetricians per shift of work at the hospital. Of the total, $56.0 \%$ of births were attended by obstetricians; $17.0 \%$ attended by midwives; $14.0 \%$ by medical students and $13.0 \%$ of the women were unable to say which professional attended the birth.

About the access to information during the service, $50.0 \%$ of the women reported receiving guidance during labor and delivery by the nursing team, $15.0 \%$ said that they were advised by the medical team, $8.0 \%$ said that they received from medical students and $27.0 \%$ said that they received from more than one of the above.

During pregnancy, $98,0 \%$ of the women reported not having participated in informative courses about pregnancy and childbirth and only $2.0 \%$ of the women participated in courses offered by the maternity hospital. Regarding the accommodation provided by the health team of the delivery room, women rated it as good (62.0\%) and satisfactory (38.0\%).

Concerning the non-pharmacological strategies for pain relief, $62.0 \%$ of the women reported using some methods available in the service and $38.0 \%$ did not use any. Of the 62 mothers who used the methods 
for pain relief, the obstetric ball was used by 27 women, a bath for immersion was used by 25 of them, and the shower was used by 36 , ambulation by 43 women, breathing techniques by 21 women, squatting by 14 and massages by 12 of them, it is emphasized that some women used more than one method of pain relief and relaxation during labor.

The practices offered to women during the service to the birth process and discussed under the framework of the World Health Organization are described in Tables 1 and 2.

Table 1 - Practices offered to women during labor, ( $\mathrm{n}=100)$, usual risk maternity hospital

\begin{tabular}{lc}
\hline Práticas & n(\%) \\
\hline Privacy & $78(78.0)$ \\
Yes & $18(18.0)$ \\
Partial & $4(4.0)$ \\
No & \\
Presence of companion & $83(83.0)$ \\
Yes & $17(17.0)$ \\
No & \\
Fasting & $54(54.0)$ \\
Yes & $46(46.0)$ \\
No & \\
Venous puncture & $53(53.0)$ \\
Yes & $47(47.0)$ \\
No & \\
Vaginal Touch & \\
Yes, every 1 hour & $63(63.0)$ \\
Yes, every two hours or more & $37(37.0)$ \\
Amniotomy & \\
Yes & $45(45.0)$ \\
\hline & \\
\hline & \\
Othere & \\
\hline
\end{tabular}

Table 2 - Practices offered to women during labor and postpartum $(\mathrm{n}=100)$, usual risk maternity hospital

\begin{tabular}{lc}
\hline Practices & $\mathbf{n}(\%)$ \\
\hline Maternal position during childbirth & \\
Lithotomy /dorsal & $83(83.0)$ \\
Lateralized & $9(9.0)$ \\
Half sitting & $4(4.0)$ \\
kneeling & $2(2.0)$ \\
Squatting & $2(2.0)$ \\
Analgesia & \\
Yes & $16(16.0)$ \\
No & $84(84.0)$ \\
Episiotomy & \\
Yes & $25(25.0)$ \\
No & $75(75.0)$ \\
Skin-to-skin after birth & \\
Yes & $84(84.0)$ \\
No & $16(16.0)$ \\
Breastfeeding in the first hour of life & \\
Yes & $95(95.0)$ \\
No & $5(5.0)$ \\
\hline
\end{tabular}

\section{Discussion}

The fertility rate in Brazil was approximately two children per woman in 2014, this has been reduced since the $1960 \mathrm{~s}^{(6)}$. The reduction in the fertility rate is apparent in the current research, since from the total interviewed the minority has three or more children.

A reduced number of births attended only by midwives was demonstrated in the maternity hospital. The role of midwives in the health system contributes to improved healthcare, aiming at a safe and humanized care $^{(1)}$. Moreover, they have been key players in the development of research that contributes to changes in obstetric practices and transformation of the care model to labor and delivery ${ }^{(7)}$.

In Brazil, one of the challenges of the moment is to find effective strategies for greater integration and 
enhancement of properly trained midwives to promote humane care and based on scientific evidence ${ }^{(7)}$.

It is noteworthy that the maternity hospital mentioned is a teaching hospital, so one highlights the actions of medical students in delivery care. However, it is also clear that the participants could not inform who attended the birth. This may be due to the fact that professionals do not identify themselves correctly. However, it is recognized that the health team in obstetrics should be prepared to accommodate women, respect that moment, because these actions facilitate and promote deeper bond of the team with the pregnant women, transmitting confidence and calm to them ${ }^{(8)}$.

Half of the participants reported that they were guided by members of the nursing team, which confirms that they received in the maternity hospital humanized care and attention from these professionals. In this perspective, it can be said that this practice corresponds to what the World Health Organization recommends, that health professionals should be engaged in care and that they should provide all the information that women want and need ${ }^{(5)}$.

It is known that one way of transmitting tranquility and confidence is information, because the lack of knowledge affects their psychological condition, which may cause feelings of fear and uncertainty, and lead to the production of hormones such as adrenaline, which stimulates the neocortex and inhibits the production of other hormones such as oxytocin, endorphin, catecholamine, necessary for the evolution of labor and delivery ${ }^{(9)}$.

However, it is also necessary to preserve the privacy of women, encouraging low light and silence, providing them with security, thus contributing to the reduction of the neocortex activity and, consequently, with the physiology of labor ${ }^{(9)}$.

Despite having undergone prenatal, almost all the women came to the maternity hospital at the moment of birth without having taken any courses about pregnancy and childbirth. Courses of this nature, offered in units of the Unified Health System can enable women experiences that deepen their knowledge about these issues, preventing them from cultivating misconceptions about the birth process.

Consequently it can be said that communication and health information between professionals and pregnant women need to be prioritized during prenatal care as it can be the best way to promote understanding of the gestational process. It is necessary to create a space for exchanging of life experiences and group experiences, as it helps participants to strengthen and face situations of change, from their experiences and from others' ${ }^{\prime(10)}$.

A concern of the Ministry of Health is also the welcoming of women in labor, in this sense this study showed that most women felt welcomed in the delivery room. It is essential for the maternity hospital to make efforts to encourage and guide professionals about how to improve welcoming. The welcoming of women and the quality of the interaction between staff and mothers are essential care actions to a humanized and attentive reception, enabling the identification of complaints, concerns, anxieties and doubts of women ${ }^{(11)}$.

The maternity hospital studied offers nonpharmacological strategies for pain relief, most participants used two or more strategies during labor. This result confirms a previous study, which proved that women who are able to move freely and to use relaxation methods during labor reported the movement as a way to find a comfortable position, usually making labor shorter than women who remained lying down, and moreover, obtained pain relief ${ }^{(10)}$.

The non-pharmacological strategies help reduce the pain by avoiding invasive interventions as well as providing comfort ${ }^{(5)}$. Corroborating the findings, this study had positive results, mentioning the use of relaxation methods, such as the obstetric ball and the walk, which favor the descent and the baby settling in the pelvis; the bathtub and the shower that decrease pain and help relaxation; breathing, which diverts attention from the pain and aims at 
mothers' and babies' physical well-being; the squat, which favors the descent of the fetal presentation; and the massage, which when carried out by the accompanying person brings a sense of relief and proximity to the companion ${ }^{(5)}$.

Women's privacy is also a very important factor, which requires the contribution of professionals to preserve it because improper exposure opposes the values advocated by humanization and the principles of integrity and individuality. The results revealed that most participants had their privacy preserved.

The presence of a companion during the parturition process is guaranteed by law ${ }^{(12)}$, although studies indicate that many women are unaware of that right $^{(13)}$.

In this research, a minority among the participants did not count on the companion at any time of the birth process. But there are many benefits from the support of an accompanying person to women during delivery. It should be their choice in order to provide encouragement, safety, feelings of satisfaction, peace and happiness, strengthening of family ties, and thus make the process of parturition a positive experience ${ }^{(13)}$.

Feeding during labor is still an issue very discussed in obstetric care. The World Health Organization and the Stork Network recommend the intake of liquids and light foods during labor, and this action is an example of respect for women's autonomy ${ }^{(3)}$.

However, the food restriction and fluid intake of women in labor are still part of an obstetric and anesthetic tradition, and are firmly defended on the grounds of reducing the risk of maternal morbidity and mortality as a result of Mendelson's syndrome, characterized by bronchoaspiration due to the presence of food waste during general anesthesia. However, there is evidence that fasting does not guarantee the absence of small gastric volumes during anesthesia $^{(14)}$

In this study it was observed that more than half of the mothers were fasting at some stage of labor.
Since the evidence shows no benefits or harms, there is no justification for the restriction of liquids and food during labor for women at low risk of complications ${ }^{(14)}$. However this restriction may be reconsidered after a clinical evaluation that justifies it.

It was also evident that more than half of the pregnant women received venous catheterization during labor. When performed routinely, this practice is considered harmful to the natural delivery, and therefore should be eliminated as it only facilitates the professional's work, if there is the need of administration of intravenous medications. However, it prevents the movements and freedom of position of pregnant women ${ }^{(5)}$ and hinders the first contact with the newborn.

As for the vaginal examination, most participants underwent this exam in a 1 hour break, a practice that is opposed to what is recommended ${ }^{(5)}$. In the first stage of labor the vaginal examination should be conducted at least every two hours or more. The amount and timing of performing vaginal examination should be considered, with discretion, to allow a proper assessment of the progress of labor ${ }^{(14)}$. However, the fact that maternity hospitals are training fields for health professionals implies the possibility that there will be an increased amount of this examination, although that is not recommended.

In the past the use of amniotomy was indicated at admission under the premise that this intervention accelerate labor ${ }^{(5)}$. However, there is scientific evidence showing that this practice causes an increase in fetal heart rate, which in turn increases the levels of $\mathrm{C}$-sections ${ }^{(13)}$. The findings of this study show that the use of amniotomy can be minimized, and there must be compelling reasons from a scientific point of view for this interference with the natural process of childbirth $^{(5)}$.

Regarding the place where the delivery was conducted, it was found that about half of the participants wandered until the delivery room already in the second stage. It is noteworthy that the maternity hospital studied has beds for pre-natal, delivery and 
post-partum period in which women can stay during labor and delivery and postpartum, without being transferred to the delivery room.

The transfer to the delivery room and the lithotomy position during labor provide comfort for the professional, however it does not favor the birth because it acts against gravity and is uncomfortable for women. So there is no need to transfer women to another environment during the second stage of labor $^{(14) .}$.

Among the objectives of the Humanization Program of the Ministry of Health there is the attention to the rights of women in labor, aimed at their effective participation and freedom in the decisions of their birth. This way, women have the freedom of choosing their position and movements during labor ${ }^{(2)}$. But in this study we observed that most women gave birth in non-vertical position and this practice is due to the Brazilian culture, institutional protocols, behavior and professional preferences ${ }^{(14)}$.

A study showed that the vertical position favors gravity, in which women reduce by $35.0 \%$ the force expended when compared to a horizontal position; and it also decreases the compression of large vessels, improves maternal and fetal circulation; increases the passage of the birth canal in up to $28.0 \%$ and is significant in the respiratory aid. When horizontally, maternal breathing is impaired ${ }^{(15)}$.

The results indicate that analgesia was performed in a minority of births which shows that it is not a routine practice in this maternity hospital. The indication of analgesia should be judicious and aimed at the painful complaint of patients, when childbirth is considered as a psychosomatic event. From the point of view of humanization of care, when a woman complains of pain and requests relief, analgesia/ anesthesia is indicated, a recommendation that was supported by the Ministry of Health ${ }^{(16)}$.

However, although analgesia provides the alleviation of women's pain during labor, it can cause side effects such as maternal hypotension secondary to sympathetic blockade, and muscle relaxation of the pelvic floor and abdominal wall, leading to difficulties in internal rotation of the fetus head in the birth canal, and the possible extension of the second stage, with increased incidence of instrumental deliveries ${ }^{(16)}$.

Regarding the use of episiotomy there is a questioning about this intervention during the birth process. This issue has been discussed for a long time, but only after the 90s scientific evidence showed the risks of episiotomy, as the biggest probability of fourth-degree perineal tear and fecal incontinence ${ }^{(17)}$ and this practice was recommended to be restricted ${ }^{(5)}$.

Aiming at women's perception of the use of episiotomy, a survey confirms that this practice should not be used routinely because it has no protective effect on the perineum ${ }^{(18)}$. The World Health Organization states that the percentage limit to be done is up to $10.0 \%$, with necessary justification and indication, and not on a routine basis ${ }^{(5)}$. In this research, it was observed that although the procedure is performed more frequently than what is recommended it was observed a downward trend.

The skin-to-skin contact between mother and baby is also a determining factor in the humanization of delivery care, described in the fourth step of the Baby Friendly Hospital Initiative, which is a strategy from the Ministry of Health to encourage exclusive breastfeeding. It is noteworthy that the maternity hospital under study presented favorable results concerning this practice, which justifies its certification as a Baby Friendly Hospital ${ }^{(3)}$.

Breastfeeding should be encouraged in the first hour after delivery, as it can reduce by $22.0 \%$ neonatal mortality ${ }^{(18)}$. The results found in this study were positive, since almost all newborns were breastfed in the first hour of life. It is important to consider that babies who did not receive breast milk in the first hour were those who needed immediate care during this period. 


\section{Conclusion}

From mothers' perspective the use of some practices during delivery and birth care should be encouraged and others eliminated. Among the practices that should be encouraged, stands out: the care with women's privacy; the participation of the companion of choice throughout the process; the use of non-pharmacological methods of pain relief during labor; mothers' encouragement of skin-to-skin contact with the newborn and breastfeeding right after birth.

However, practices that should be used with caution or eliminated from delivery care and that were mentioned by mothers were found such as: the transfer of women during the second stage to the delivery room; the lithotomy position during birth; fasting during labor, routine venipuncture, vaginal examinations in a short period of time and by more than one professional and episiotomy routinely.

It can be noticed that women are unaware of their rights and remain passive in their delivery process. This happens in spite of the institutional efforts to change the care model during labor and birth. So it is necessary that women take ownership at the best practices so that they have autonomy and receive care in the humanized delivery perspective.

Women's participation becomes essential because only they can really demonstrate if the care practice offered has responded to what was proposed by public policies.

This research also allowed the approach between theoretical and practical knowledge of obstetric nurses in health institutions, demonstrating that changes in care practices towards the new model of care during labor and birth has been consolidated. So other studies should be conducted in other institutions from the perspective of mothers and also with other subjects, such as health professionals and managers.

\section{Collaborations}

Apolinário D participated in the project design, collection, analysis and interpretation of data, article writing and approval for publication. Rabelo M and Souza SRRK contributed to the project design, analysis and interpretation of data, article writing and approval for publication. Wolff LDG and Leal GCG contributed to the critical review of the article content and final approval of the version to be published.

\section{References}

1. Ministério da Saúde (BR). Humanização do parto e do nascimento. Brasília: Ministério da Saúde; 2014.

2. Ministério da Saúde (BR). Programa de Humanização do Parto, Pré-natal e nascimento. Brasília: Ministério da Saúde; 2002.

3. Ministério da Saúde (BR). Secretaria de Atenção à Saúde, Departamento de Ações Programáticas Estratégicas. Política nacional de atenção integral à saúde da mulher: princípios e diretrizes. Brasília: Ministério da Saúde; 2011.

4. Ministério da Saúde (BR). Rede Cegonha. Diretrizes gerais e operacionais da Rede Cegonha. Brasília: Ministério da Saúde; 2011.

5. Ministério da Saúde (BR). Portaria n. 1.459/GM, de 24 de junho de 2011. Institui, no âmbito do Sistema Único de Saúde - SUS - a Rede Cegonha. Brasília: Ministério da Saúde; 2011.

6. Instituto Brasileiro de Geografia e Estatística. Taxa de fecundidade total - Brasil 2000 a 2015. Rio de Janeiro: IBGE; 2015.

7. Narchi NZ, Cruz EF, Gonçalves R. O papel das obstetrizes e enfermeiras obstetras na promoção da maternidade segura no Brasil. Ciênc Saúde Coletiva. 2013; 18(4):1059-68.

8. Gomes ARM, Pontes DS, Pereira CCA, Brasil AOM, Moraes LCA. Assistência de enfermagem obstétrica na humanização do parto normal. Rev Cient Enferm. 2014; 4(11):23-7. 
9. Odent M. A cientificação do amor. São Paulo: Terceira Margem; 2000.

10. Souza VB, Roecker S, Marcon SS. Ações educativas durante a assistência pré-natal: percepção de gestantes atendidas na rede básica de MaringáPR. Rev Eletr Enf. [periódico na Internet]. 2011 [citado 2014 out 07]; 13(2):199-210. Disponível em: https://www.fen.ufg.br/fen_revista/v13/n2/ v13n2a06.htm

11. Santos LM, Pereira SSC, Santos VEP, Santana RCB, Melo MCP. Relacionamento entre profissionais de saúde e parturientes: um estudo com desenhos. Rev Enferm UFSM. 2011; 1(2):225-37.

12. Gonzalez AD, Fernandes ES, Silva EF, Rabelo M, Souza SRRK. A percepção do acompanhante no processo do nascimento. Cogitare Enferm. 2012; 17(2):310-4.
13. Singata M, Tranmer, J, Gyte, GM. Restricting oral fluid and food intake during labour. Cochrane Database Syst Rev. 2010; 1:CD003930.

14. Porto AMF, Amorim MMR, Souza ASR. Assistência ao primeiro período do trabalho de parto baseada em evidências. Rev Femina. 2010; 38(10):527-37.

15. Sabatino H. Análise crítica dos benefícios do parto normal em distintas posições. Rev Tempus Actas Saúde Coletiva. 2010; 4(4):143-8.

16. Cunha AA. Analgesia e anestesia no trabalho de parto e parto. Femina. 2010; 38(11):599-606.

17. Carvalho CCM, Souza ASR, Moraes Filho OB. Episiotomia seletiva: avanços baseados em evidências. Femina. 2010; 38(5):265-70.

18. Boccolini CS, Carvalho ML, Oliveira MIC, Escamilla RP. Breastfeeding during the first hour of life and neonatal mortality. J Pediatr. 2013; 89(2):131-6. 